\title{
Stmn1 up-regulates $C d \times 2$ expression and participates in gastric intestinal metaplasia in vitro and in vivo: a randomized controlled trial
}

Xuan Chen ( $\nabla$ chenxuan001564@163.com )

Zhejiang Academy of Traditional Chinese Medicine https://orcid.org/0000-0001-5776-4931

\section{Lizuan Chen}

Zhejiang Tianhuang Pharmaceutical, Co. Ltd

\section{Zeming Ren}

Zhejiang Academy of Traditional Chinese Medicine

\section{Yeling Tong}

Zhejiang Academy of Traditional Chinese Medicine

\section{Guanhai Dai}

Zhejiang Academy of Traditional Chinese Medicine

\section{Sisi Chen}

Zhejiang Academy of Traditional Chinese Medicine

\section{Renzhao Wu}

Zhejiang Academy of Traditional Chinese Medicine

\section{Research article}

Keywords: Stmn1, Cdx2, IM, rats, GES-1 cell line

Posted Date: August 6th, 2020

DOI: https://doi.org/10.21203/rs.3.rs-42824/v1

License: (9) (i) This work is licensed under a Creative Commons Attribution 4.0 International License. Read Full License 


\section{Abstract}

BACKGROUND AND PURPOSE: Stmn1 is over-expressed in almost all pathological stages during gastric cancer development, such as chronic atrophic gastritis, dysplasia, and gastric cancer. IM is an important precancerous lesion of gastric cancer, however, whether Stmn1 was up-regulated or down-regulated in this stage is still unknown. We aimed to evaluate the expression level of Stmn1 in IM in vivo and its relationship with important gene of IM named $C d x 2$ in vitro.

EXPERIMENTAL APPROACH: Wistar rats ( $\mathrm{n}=12$, sex in half) were gavaged with MNNG $(167 \mu \mathrm{g} / \mathrm{ml})$ to induce IM model in stomach. After pathological examination with $A B$ staining to confirm that the model was successful, relative expression level of Stmn 1 was detected between normal group and model group using RT-qPCR. Human gastric cell line GES-1 was used to investigate whether Stmn 1 influence expression level of IM essential gene $C d x 2$ by over-expressing or down-expressing experiments, RT-qPCR and western blot.

KEY RESULTS: We have demonstrated that Stmn 1 was up-regulated in IM model induced by MNNG in rats in vivo, and it could significantly up-regulate $C d x 2$ expression level in human gastric cell line GES-1 in vitro.

CONCLUSIONS AND IMPLICATIONS: We demonstrated that Stmn1 was involved in IM in this model and it could up-regulating $C d x 2$ in human gastric cell line GES-1 in vitro. These results suggested that Stmn 1 might be a potential biomarker or candidate treatment target of IM in stomach.

\section{Background}

There were 1,033, 701 new gastric cancer cases worldwide in 2018 (WHO). IM (IM), which refers to the transformation of gastric epithelium into intestinal phenotype, is the most common precancerous lesion of gastric cancer [1, 2]. Control and reversion of precancerous lesions is the key point to prevent deteriorating into gastric cancer. Cognition of the mechanisms of precancerous lesions is a prerequisite.

Caudal type homeobox gene $2(C d x 2)$, a transcription factor, is believed to be essential in cell differentiation of intestinal epithelium [3]. Cdx2 Ectopic expression in gastric tissue is an important mechanism of IM [4-8]. Cdx2 controls the expression of multiple intestinal proteins, such as MUC2 [9, 10], LI-cadherin [11], ST6GaINAc-I [12]. Besides, $C d \times 2$ is activated by Oct-1 [13] and inhibited by RUNX3 [14] and inhibit $S H H[15]$ in IM in stomach.

Stathmin 1 (Stmn1) belongs to the stathmin gene family, and the protein it encoded prevents assembly and promotes disassembly of microtubules. In gastric cancer, Stmn 1 expression level is up-regulated [16], and it positively correlated with lymph node metastasis, TNM stages and vascular invasion, and negatively with recurrence-free survival [17]. Stmn 1 gene silencing could suppress proliferation, migration and invasion of gastric cancer cells via AKT/SCLU and STAT3 signaling [17-20]. Over-expression of 
Stmn1 is associated with poor prognosis of patients with gastric cancer [21]. However, its expression in $\mathrm{IM}$ is unknown.

The gastric cancer model [22] induced by 1-methyl-3-nitro-1-nitrosoguanidine (MNNG) in rats can simulate the whole process from normal human gastric to chronic gastritis, chronic atrophic gastritis, IM, intraepithelial neoplasia, gastric adenocarcinoma, the most common type of gastric cancer in human [23], which provides possibility and sufficient window period for drug intervention to prevention or treatment of gastric cancer.

Previously, we found that Stmn 1 is significantly higher expressed in chronic atrophic gastritis in rats [24], here we investigate whether Stmn 1 and IM in stomach of IM model rat, and detected the effect of Stmn1 on the expression of $C d x 2$ in human gastric cells GES-1.

\section{Methods}

\section{Rat experiments}

Twenty-four 6-week-old wistar rats, weighing around 200g, were bought from Shanghai SLAC Laboratory Animal Co. Ltd (Shanghai, China) and randomly divided into normal control group $(n=12)$ and model group $(n=12)$ using stratified random sampling, sex in half. All rats were kept on a 12-hour light-dark cycle in a pathogen-free animal feeding facility at Zhejiang Academy of Traditional Chinese Medicine. The maximum caging density was six mice. The animal study protocols were approved by the Medical Ethics Committee of Tongde Hospital of Zhejiang Province [No. (2016)040] before experiments.

Rats in the model group were provided with ample fresh MNNG solution $(167 \mu \mathrm{g} / \mathrm{ml})$ stored in light-free bottles for 20 weeks. On the last day, all rats were anesthetized by intraperitoneal injection of pentobarbital sodium $(50 \mathrm{mg} / \mathrm{kg}, 2 \%$ ), then stomachs were removed along with $0.5 \mathrm{~cm}$ of esophagus above the stomach and $1.5 \mathrm{~cm}$ of duodenum below the stomach. After these, liver and blood of each rats were collected for further experiments, as a result every rat was sacrificed on test-bed. Each stomach was vertically divided into 2 parts; one part was frozen in liquid nitrogen for total RNA isolation, and the other part was fixed in $10 \%$ formalin. AB staining was used to observe the IM of gastric mucosa (goblet cells).

For each rat, five different investigators were handled as follows: a first investigator (RZ) administered the treatment following stratified random sampling and the randomization table. A second investigator (CY) was responsible for the anaesthetic procedure, whereas a third investigator (CX, TY, CS, DG) performed the surgical and fix procedure. A fourth investigator (ZF) (also unaware of treatment) performed pathological section and evaluation of pathological results. Finally, a fifth investigator (WR) performed data analysis.

\section{Cell experiments}

Human gastric GES-1 cell line was obtained from the cell bank of Chinese Academy of Sciences (Shanghai, China) and was cultured in 1640 medium with $10 \%$ fetal bovine serum at $37^{\circ} \mathrm{C}$ in a $5 \% \mathrm{CO} 2$ 
atmosphere. Cells were divided into 5 groups: normal control group, $C d x 2$ over-expression group, $C d x 2$ over-expression $+S t m n 1$ over-expression group, $C d x 2$ over-expression + Stmn 1 over-expression+ Stmn 1 siRNA group, $C d x 2$ over-expression + Stmn 1 siRNA group. Cdx2 plasmid, Stmn 1 plasmid and siRNA (Forward: 5'-GUAGGACUGUAUAGGUAGATT-3'; Reverse: 5'-TTCAUCCUGACAUAUCCAUCU-3') were designed and synthesized by GenePharma. Transfection was performed in 24-well ( $n=6$; for RT-qPCR; Cdx2 plasmid, 1 pg/well; Stmn 1 plasmid, 20 pg/well; Stmn1 siRNA, 10 pM) or 6-well ( $n=3$; for WB; $C d x 2$ plasmid, 4 pg/well; Stmn 1 plasmid, 80 pg/well; Stmn1 siRNA, 40 pM) culture vessels using 0.5ul/well or 2 ul/well lipo2000 (invitrogen), respectively.

\section{Histological section assay}

The rat stomach samples in formalin were embedded in paraffin and sliced at $4-\mu m$ thickness. The slices were then separately stained with AB-PAS following routine procedures. Sections were examined under light microscope. The investigator was blind to group assignment and outcome assessment. IM was determined according to intestinal type cells in gastric gland cells.

\section{RT-qPCR}

The RT reaction was performed using $500 \mathrm{ng}$ of total RNA according to the manufacturer's instructions (RR036A, Takara). The qPCR reactions were performed on the StepOnePlus system (ABI) with the SYBR® Premix ExTaqTM kit (RR820A, Takara). The endogenous control gene was RPL13A for cell experiments and $E F-1 a$ for rat experiments. The relative expression levels were calculated using the $2^{-\triangle} \triangle \mathrm{Ct}$ method [25]. Primers were as follows: Stmn 1 (rat, homo), Forward: 5'- TGGCAGAGGAGAAACTGACC-3', Reverse: 5'TTCTTCCGCACCTCTTCAAC-3'; Cdx2 (homo), Forward: 5'- TTCACTACAGTCGCTACATCACCAT-3', Reverse: 5'- TTGTTGATTTTCCTCTCCTTTGCT-3' [12]; EF-1a (rat), Forward: 5'- CGAGCCACCATACAGTCAGA-3', Reverse: 5'- CCATTCCAACCAGAAATTGG-3'; RPL 13K (homo), Forward: 5'- GCCCTCCAATCAGTCTTCTG-3', Reverse: 5'- CATAGGAAGCTGGGAGCAAG-3'.

\section{Western blot protein analysis}

Protein was isolated from GES- 1 cells at $0^{\circ} \mathrm{C}$ using Whole Cell Lysis Assay (KGP250, KeyGEN BioTECH) and quantified by BCA Protein Assay Kit (P0012, Beyotime Biotechnology). A capillary-based Wes Simple Western Analysis (ProteinSimple ${ }^{\circledR}$ ) was used to detect protein abundance according to the manufacturer's protocol. In brief, $0.6 \mu \mathrm{g}$ whole protein sample was loaded into each well, and Size Range of the separation matrix was $12-230 \mathrm{kDa}$. Target proteins were identified with following primary antibodies: $C d x 2$ (12306; Cell Signaling Technology $\left.{ }^{\circledR}\right)$, Stmn1 (3352; Cell Signaling Technology $\left.{ }^{\circledR}\right)$, SOX2 (23064; Cell Signaling Technology $\left.{ }^{\circledR}\right)$. GAPDH (60004-1-Ig; Proteintech $\left.{ }^{\circledR}\right)$ was used as a reference control. According to primary antibodies, mouse or rabbit secondary antibodies provided by the manufacturer were used. Chemiluminescent signals were detected and quantified using Compass Software (ProteinSimple), the area value was used as the protein expression level.

\section{Statistical analysis}


SPSS Statistics 17.0 was used to analyze the data. Body weight and gene expression level among 5 groups were analyzed using one way ANOVA, and between 2 groups were analyzed using independent sample t-tests. Differences were considered statistically significant at $P<0.05$.

\section{Results}

\section{Stmn1 was significantly higher expressed in IM in stomach tissues in rats}

To investigate whether Stmn1 is over-expressed in IM, we detected its expression level in MNNG induced IM in stomach of rats. In typical pictures of pathological sections (Fig 1a.), there was a very small amount of blue staining in the deep part of gastric mucosa in the antrum of normal stomach; there was blue staining in the whole layer from the deep part to the shallow part of the antrum mucosa, and there were goblet cells, which are the sign of IM. In model group, there were $10 \mathrm{IM}$ rats, the other 2 rats failed to be induced into IM model 1 Then we divided all 24 rats in the normal group and model group into two groups: the group without IM $(n=14)$ and the group with IM ( $n=10)$. The $t$-test showed that the expression level of Stmn 1 in IM group was significantly higher than that in normal group ( $P=0.003$; Fig $1 \mathrm{~b}$ ). The relationship between Stmn 1 and important genes of intestinal meplasia, such as $C d x 2$ needed to be established. However, we could not detect the expression of $C d x 2$, a key regulatory gene of IM, in rat IM gastric tissue, and no other literature has reported about $C d \times 2$ in IM model rats induced by MNNG.

\section{Stmn 1 significantly up-regulates $C d \times 2$ expression level in GES-1 cells}

To explore the effect of $S t m n 1$ on $C d x 2$, we over-expressed or knock-down its expression along with overexpression of $C d x 2$ in GES-1 cells (Fig 2).

Relative mRNA expression level of $C d x 2$ and $S t m n 1$ in each group was detected by RT-qPCR. The results showed that $C d x 2$ was not expressed in normal group (Fig 3). Among other 4 groups, relative expression level of $C d \times 2$ was tested by Levene variance homogeneity test and the variance of each group was not homogeneous $(P=0.011)$, then one-way ANOVA of grouping design was used to evaluate the difference, and the results showed that the expression level of $C d x 2$ among 4 groups was significantly different $(F=$ 65.179, $P=0.000$; Fig 3). Compared with $C d x 2$ over-expression group, $C d x 2$ expression level in $C d x 2$ overexpression + Stmn 1 over-expression group was significantly higher $(P=0.000 ;$ Fig 3 .), indicating that Stmn 1 could significantly up-regulate $C d x 2$ expression level. Compared with $C d x 2$ over-expression + Stmn 1 over-expression group, $C d x 2$ expression level in $C d x 2$ over-expression $+S t m n 1$ over-expression + Stmn 1 siRNA group decreased significantly ( $P=0.000$; Fig 3 .), which was lower than that in $C d x 2$ group ( $P=0.046$; Fig 3.), indicating that blocking the over-expression of Stmn1, $C d x 2$ was significantly down regulated. However, expression level of $C d x 2$ was no difference between $C d x 2$ over-expression group and Cdx2 over-expression+Stmn 1 siRNA group.

Relative protein expression level of $C d x 2$ and $\operatorname{Stmn} 1$ in each group was detected by western blot on Wes instrument ( $\mathrm{n}=3$; Fig $4 a, b) . C d x 2$ was not expressed on protein level in normal group, which consistent with mRNA level results. In the other 4 groups, $C d \times 2$ protein abundant among groups was significantly 
different $(F=56.622, P=0.000)$. Compared with $C d x 2$ over-expression group, the protein level of $C d x 2$ in $C d x 2$ over-expression $+S t m n 1$ over-expression group was significantly higher $(P=0.006)$, indicating that Stmn 1 could significantly up regulate $C d x 2$ on protein level, which support the mRNA level results. Compared with $C d x 2$ over-expression $+S t m n 1$ over-expression group, $C d x 2$ protein abundance in $C d x 2$ over-expression $+S t m n 1$ over-expression $+\operatorname{Stmn} 1$ siRNA group was significantly lower $(P=0.000)$, indicating that blocking Stmn 1 over-expression, $C d x 2$ protein expression was significantly inhibited. Compared with $C d x 2$ over-expression group, $C d x 2$ protein expression level in $C d x 2$ over-expression + Stmn 1 siRNA group did not change $(P=0.540)$, indicating that blocking Stmn 1 expression, $C d x 2$ protein level expression did not change, consistent with mRNA level change.

\section{Discussion}

Gastric cancer is one of the most common malignant tumors worldwide. The chains of process from normal gastric mucosa to intestinal type gastric carcinoma include superficial gastritis, atrophic gastritis, IM, dysplasia, carcinoma, metastasis [23]. We found it over-expressed in chronic atrophic gastritis in rats [24]. Here we found that Stmn1 was up-regulated in IM in stomach in rats. Moreover, it could induce significant higher expression of $C d x 2$, a key gene in IM, in human gastric GES-1 cells, which suggested that Stmn 1 might involve in the development of IM by up-regulating $C d \times 2$. These results initially fill the IM gap of expression level of Stmn1 in development of gastric cancer. However, clinical evidences about whether Stmn1 was over-expressed in IM and/or chronic atrophic gastritis in patients need to be studied further.

Over-expression of Stmn 1 alone did not induce $C d x 2$ expression, indicating that $S t m n 1$ could not trigger $C d x 2$ expression, but promoted $C d x 2$ expression.

Down-regulation of $S t m n 1$ in $C d x 2$ over-expressed group did not inhibit the expression of $C d x 2$, indicating that low expression level Stmn 1 could not regulate $C d x 2$ and also knock-down low expression Stmn 1 could not effect $C d x 2$. Only over-expressed $S t m n 1$ could promote $C d x 2$ expression, and knock-down high expression level Stmn 1 could inhibit over-expressed $C d x 2$.

Over-expression of $C d x 2$ alone had no effect on $S t m n 1$ expression, indicating that $C d x 2$ could not affect the expression level of Stmn 1 .

\section{Conclusions}

Stmn1 was up-regulated in IM in rats in vivo and it could significantly up-regulate an IM essential gene $C d x 2$ in human gastric GES-1 cells in vitro. All these results suggested that Stmn1 might involve in the development of IM by up-regulating $C d x 2$.

\section{List Of Abbreviations}


IM: IM; Cdx2: Caudal type homeobox gene 2; Stmn1: Stathmin 1; MNNG: N-methyl-N'-nitro-Nnitrosoguanidine.

\section{Declarations}

\section{Ethics approval and consent to participate}

The animal study protocols were approved by the Medical Ethics Committee of Tongde Hospital of Zhejiang Province [No. (2016)040]

\section{Consent for publication}

Not applicable.

\section{Availability of data and materials}

All data generated or analysed during this study are included in this published article.

\section{Competing interests}

The authors declare that they have no competing interests.

\section{Funding}

This work was supported by the National Natural Science Foundation of China [grant number, 81703789], Talent Project of Zhejiang Association for Science and Technology [grant number, 2018YCGC007] 『major new drug discovery of important national science and technology projects [grant number, 2016ZX09101069], key social development projects of the Zhejiang province major science and technology projects [grant number, 2009C13032], Natural Science Foundation of Zhejiang Provincial [grant number, LQ18H280010]. Funding bodies did not participate in the design of the study, collection, analysis, and interpretation of data or in writing the manuscript.

\section{Authors' contributions}

$\mathrm{XC}, \mathrm{LC}$ and RW generated the conception; $\mathrm{XC}$ and GD designed the work; $\mathrm{XC}, \mathrm{ZR}, \mathrm{YT}, \mathrm{SC}$ completed the experiments and analyzed the data. $\mathrm{XC}$ was a manor contributor in writing the manuscript. All authors read and approved the final manuscript.

\section{Acknowledgements}

Not applicable.

\section{References}


[1] Jiang JX, Liu Q, Zhao B, Zhang HH, Sang HM, Dialeel SM. Risk factors for IM in a southeastern Chinese population: an analysis of 28,745 cases. J. Cancer. Res. Clin. Oncol. 2017;143:1-10.

[2] Li D, Bautista MC, Jiang SF, Daryani P, Brackett M, Armstrong MA. Risks and predictors of gastric adenocarcinoma in patients with gastric IM and dysplasia: a population-based study. Am. J. Gastroenterol. 2016;111:1104-13.

[3] Lorentz O, Duluc I, Arcangelis AD, Simon-Assmann P, Kedinger M, Freund JN. Key role of the Cdx2 homeobox gene in extracellular matrix-mediated intestinal cell differentiation. J. Cell. Biol. 1997;139 1553-65.

[4] Silberg DG, Sullivan J, Kang E, Swain GP, Moffett J, Sund NJ. Cdx2 ectopic expression induces gastric IM in transgenic mice. Gastroenterology. 2002;122:689-96.

[5] Almeida R, Silva E, Santos-Silva F, Silbery DG, Wang JF, Bolos CD. Expression of intestine-specific transcription factors, CDX1 and Cdx2, in IM and gastric carcinomas. J. Pathol. 2003;199:36-40.

[6] Barros R, Camilo V, Pereira B, Freund JN, David L, Almeida R. Pathophysiology of IM of the stomach: emphasis on Cdx2 regulation. Biochem. Soc. Trans. 2010;38:358-63.

[7] Barros R, Freund JN, David L, Almeida R. Gastric IM revisited: function and regulation of Cdx2. Trends. Mol. Med. 2012;18:555-63.

[8] Camilo V, Garrido M, Valente P, Ricardo S, Amaral AL, Barros R. Differentiation reprogramming in gastric IM and dysplasia: role of SOX2 and Cdx2. Histopathology. 2015;66:343-50.

[9] Mesquita P, Jonckheere N, Almeida R, Ducourouble MP, Serpa J, Silva E, et al. Human MUC2 mucin gene is transcriptionally regulated by $\mathrm{Cdx}$ homeodomain proteins in gastrointestinal c arcinoma cell lines. J. Biol. Chem. 2003;278:51549-56.

[10] Yamamoto H, Bai YQ, Yuasa Y. Homeodomain protein Cdx2 regulates goblet-specific MUC2 gene expression. Biochem. Biophys. Res. Commun. 2003;300:813-8.

[11] Hinoi T, Lucas PC, Kuick R, Hanash S, Cho KR, Fearon ER. Cdx2 regulates liver intestine-cadherin expression in normal and malignant colon epithelium and IM. Gastroenterology. 2002;123:1565-77.

[12] Pinto R, Barros R, Pereira-Castro I, Mesquita P, Costa LT, Bennett EP, et al. Cdx2 homeoprotein is involved in the regulation of ST6GaINAc-I gene in IM. Lab. Invest. 2015;95:718-27.

[13] Qian J $\llbracket$ Kong X XDeng N, Tan P, Chen H, Wang J, et al. OCT 1 is a determinant of synbindin-related ERK signalling with independent prognostic significance in gastric cancer. Gut. 2015;64:37-48.

[14] Fukamachi H, Ito K, Ito Y. Runx3-/- gastric epithelial cells differentiate into intestinal type cells. Biochem. Biophys. Res. Commun. 2004;321:0-64. 
[15] Mutoh H, Hiroyuki H, Sashikawa M, Sakamoto H, Sugano K. Direct repression of Sonic Hedgehog expression in the stomach by Cdx2 leads to intestinal transformation. Biochem. J. 2010;427:423-34.

[16] Kang W, Tong JH, Chan AW, Lung RWM, Chau SL, Wong N, et al. Stathmin1 plays oncogenic role and is a target of microRNA-223 in gastric cancer. Plos One. 2012;7:e33919.

[17] Jeon TY, Han ME, Lee YW, Lee YS, Oh SO. Over-expression of stathmin1 in the diffuse type of gastric cancer and its roles in proliferation and migration of gastric cancer cells. Br. J. Cancer. 2010;102:710-8.

[18] Shu F, Zou X, Tuo H, She S, Huang J, Ren H, et al. Stathmin gene silencing suppresses proliferation, migration and invasion of gastric cancer cells via AKT/sCLU and STAT3 signaling. Int. J. Oncol. 2019;54:1086-98.

[19] Meng ZJ, Tao K. Enhancement of chemosensitivity by stathmin-1 silencing in gastric cancer cells in situ and in vivo. Oncol. Res. 2016;23:35-41.

[20] Akhtar J, Wang Z, Zhang ZP, Bi MM. Lentiviral-mediated RNA interference targeting stathmin1 gene in human gastric cancer cells inhibits proliferation in vitro and tumor growth in vivo. J. Transl. Med. 2013;11:212.

[21] Ke B, Wu LL, Liu N, Zhang RP, Wang CL, Liang H. Over-expression of stathmin 1 is associated with poor prognosis of patients with gastric cancer. Tumour. Biol. 2013;34:3137-45.

[22] Su Q, Luo ZY, Teng H, Yun WD, Li YQ, He XE. Effect of garlic and garlic-green tea mixture on serum lipids in MNNG-induced experimental gastricarcinoma and precancerous lesion. World J Gastroenterol. 1998;4(1):29.

[23] Correa P, Shiao Y. Phenotypic and genotypic events in gastric carcinogenesis. Cancer Res. 1994;54:1941s-3s.

[24] Chen X, Yang FL, Dai GH, Wu Y, Ren ZM, Wu RZ. Molecular mechanism of Granule Dendrobii in the treatment of chronic atrophic gastritis rats induced by MNNG. Chin. J. Tradit. Chin. Med. Pharm. 2019;34:5633-6.

[25] Livak KJ, Thomas DS. Analysis of relative gene expression data using real-time quantitative PCR and the $2^{-\triangle \Delta C t}$ method. Methods. 2001;25:402-8.

\section{Figures}




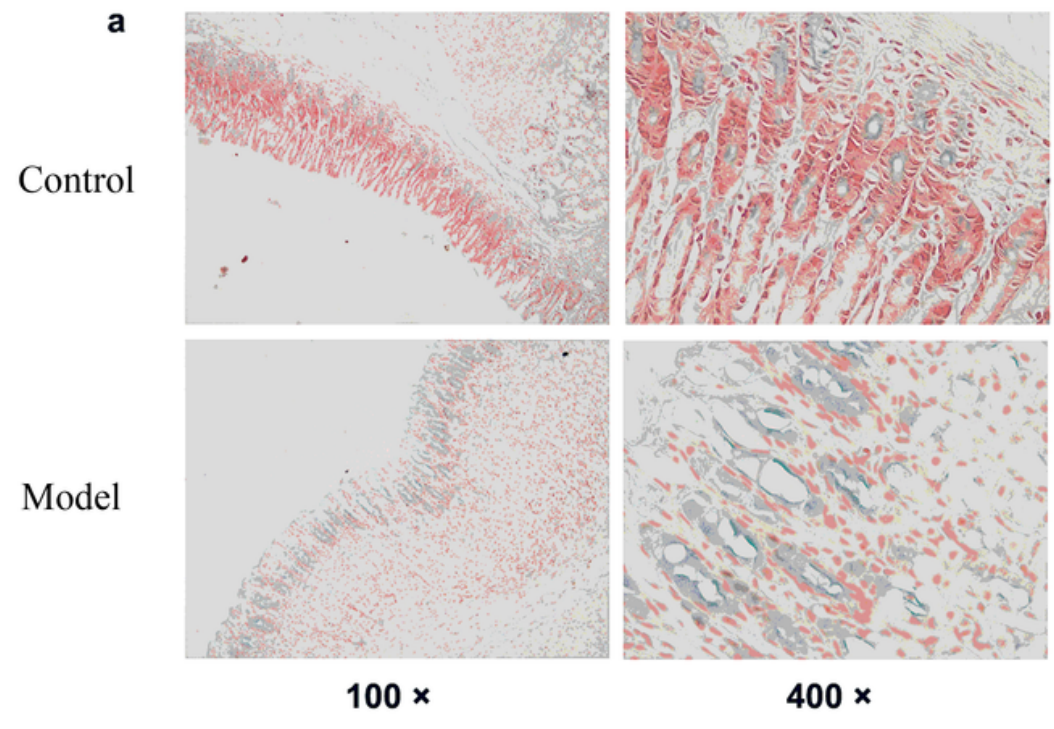

b

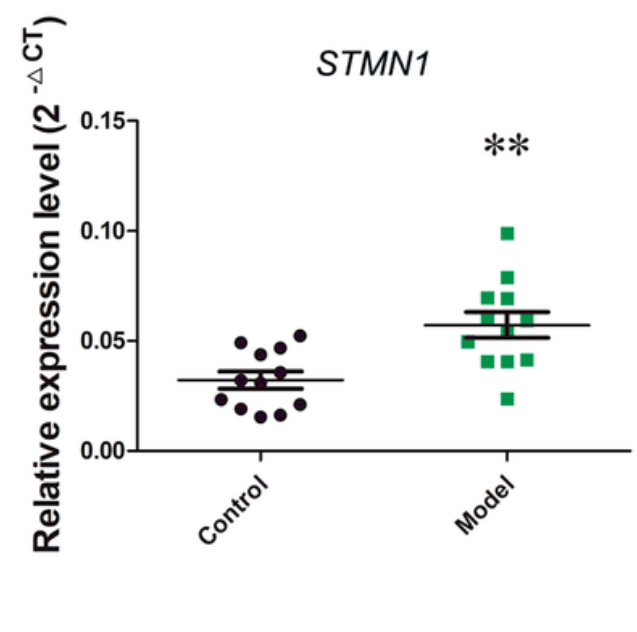

Figure 1

Photographs of pathological sections of IM in stomach of rats (AB staining $囚 a$ ) and expression difference of Stmn1 between normal gastric tissue and IM (b)

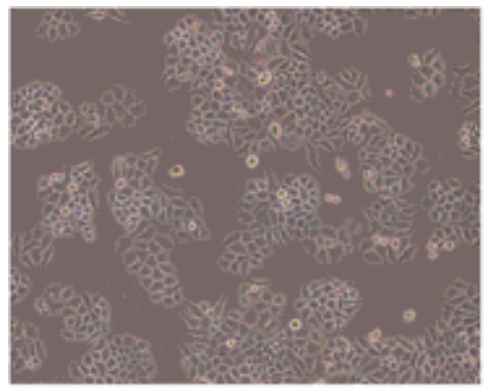

Control

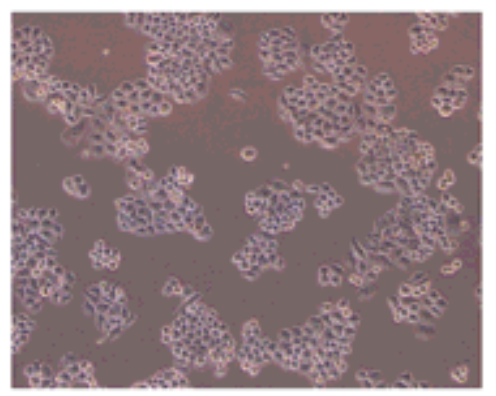

CDX2 $\uparrow+$ STMN1 $\uparrow+$ STMN1

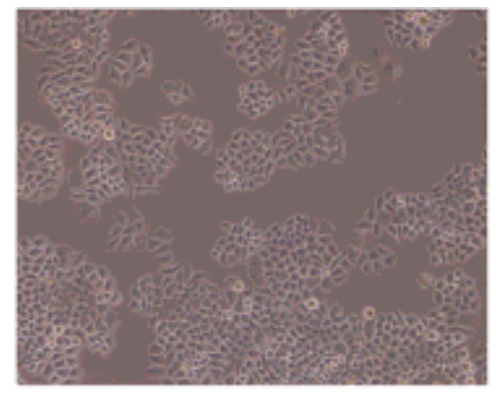

$\operatorname{CDX} 2 \uparrow$

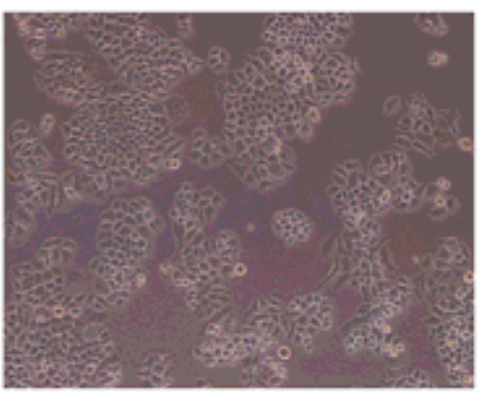

CDX2 $\uparrow+$ STMN1

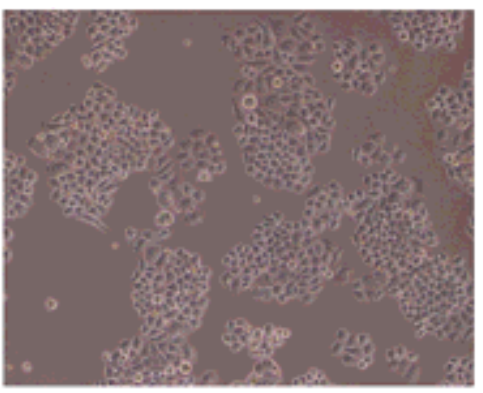

$\operatorname{CDX} 2 \uparrow+$ STMN1 $\uparrow$

Figure 2

Photographs of cells in each group (10x) 


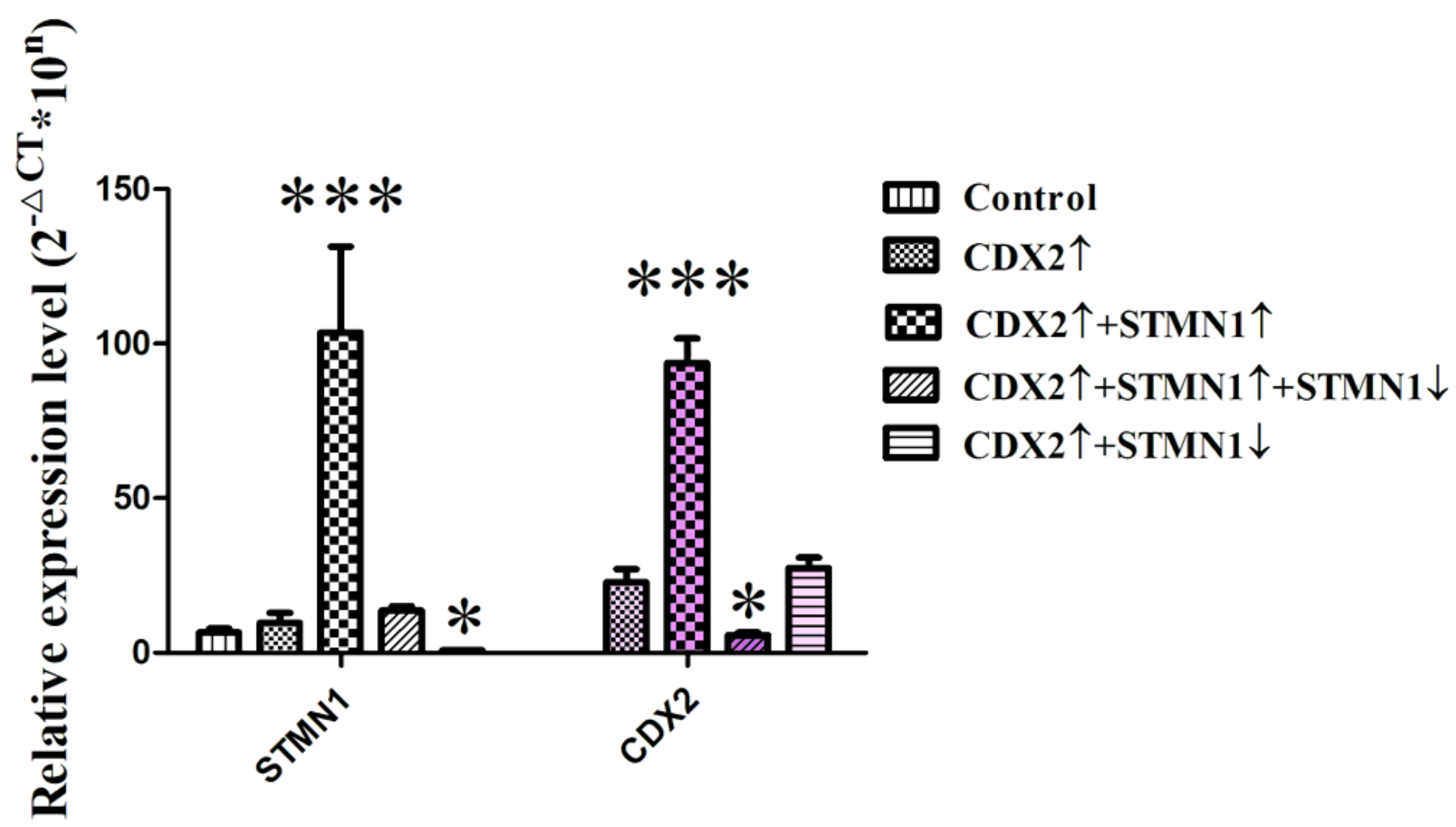

Figure 3

Stmn 1 and Cdx2 relative expression level among groups using RT-qPCR Compared with CDX1 overexpression group, ${ }^{*} \mathrm{P}<0.05,{ }^{*} * \mathrm{P}<0.001$ 


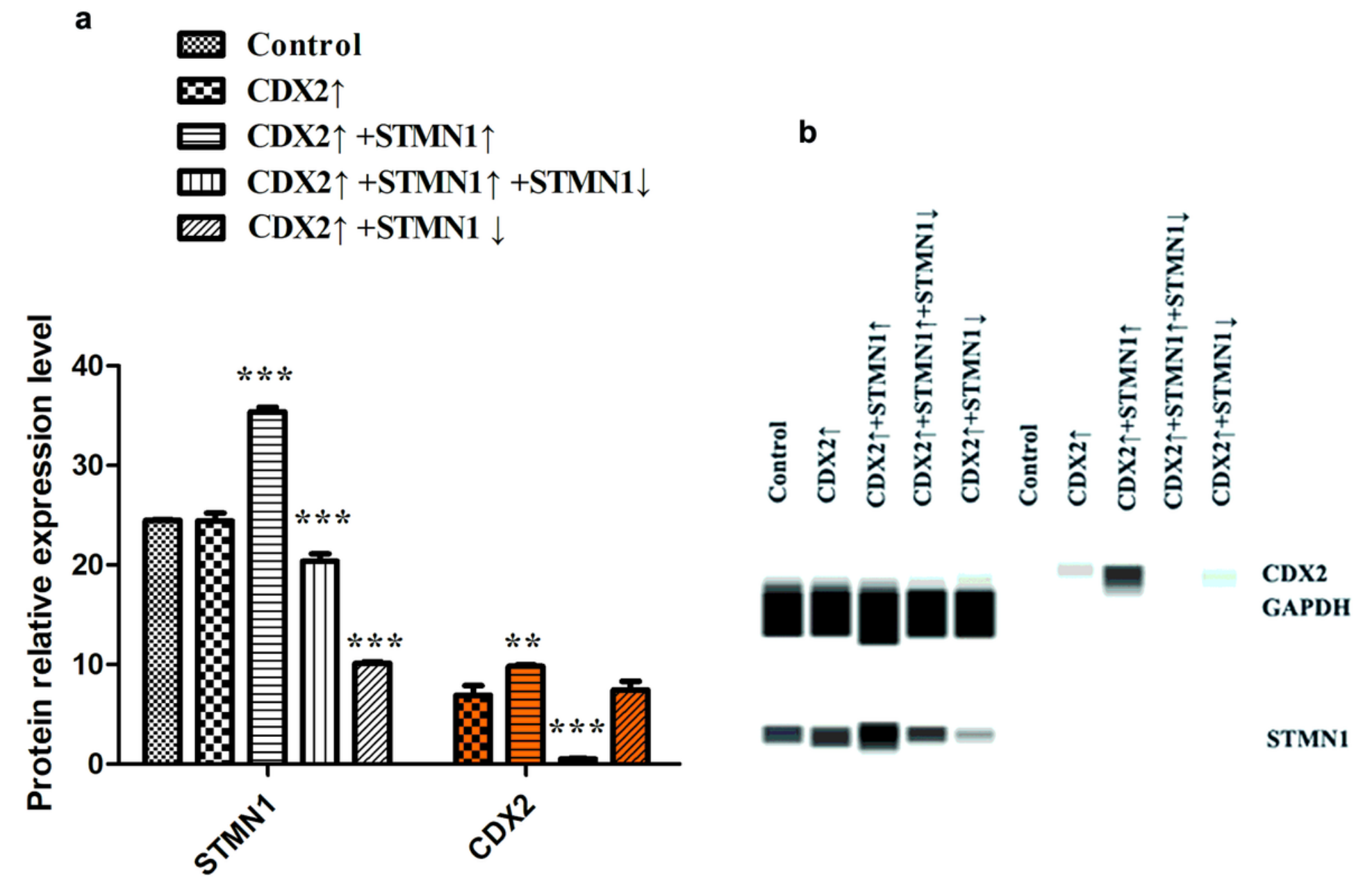

Figure 4

Comparison of $\mathrm{Cdx} 2$ protein abundance (area value) in each group by western blot ${ }^{\star \star} P<0.01 \mathrm{D}^{\star \star \star} \mathrm{P}<0.001$ (a) and representative western blots of Cdx2, Stmn1 and GAPDH in each group (b)

\section{Supplementary Files}

This is a list of supplementary files associated with this preprint. Click to download.

- ARRIVEchecklist.doc

- Additionalfigure.tif 